\section{EXECUTIVE CORRESPONDENCE - A BETTER WAY}

Serafina Sebastyan

Have you ever written to a government department and been amazed at how long it took to receive a reply? Were you then astounded upon reading the letter to find that you needed your oxford Dictionary and Roget's Thesaurus nearby to try and understand what they were saying? Finally, were you totally frustrated and angered to discover that after plowing through two solid pages of text that the reply merely sald "no" to your request?

We11, If you can answer "yes" to any of the above questions, then please read on because we can give you hope:

"We" are specifically a small group of employees within the federal government department of Transport Canada known as the Executive Correspondence Unit. Before I give a brief description of the role of the Unit, a look at the history of this group is in order.

Transport Canada is a huge organization comprising approximately 22,000 employees and covering the broad ranges of air, marine and surface matters. The Minister of Transport recelves an average of 600 to 800 letters a month, not including the occasional write-in campaign which can generate 2000 to 3000 letters within a matter of weeks. Before 1981, all this correspondence was distributed for reply throughout the department via the Deputy Minister's office not to be seen again for weeks, months, years, perhaps never:

Writing styles were as varied as the number of employees who handled the correspondence--and in both offictal languages no less! (Are you beginning to get the picture?)

It became very obvious that a better system needed to be found and indeed 1t was. The result of an in-house management consultant study was the implementation of a centralized, correspondence writIng and control service called the Executive Correspondence Unit (DSC). The Unit comprises French and English writers, word processIng operators, a mini-computer operator, and clerical staff. Briefly, the main objectives of the system are to provide: -a high quality of writing in both official languages -a computerized tracking and controlling of correspondence as it moves throughout the department

-full typing and photocopying services for final replies, and -overall increased efficiency and effectiveness for handling Ministerial correspondence.

The Unit has been in operation for three years and 1 th has been generally recognized by senior managers that the concept works extremely well. It has also been unanimously agreed that the quality of Ministerial correspondence within Transport has improved significantly. Trying to identify and hire good writers to maintain this high level of quality, however, is not an easy task.

Every applicant for a writer's position within DSC must possess at least a B.A. In a related fleld, have some writing or editing experience in developing editorial quality and format standards. If the applicant meets these three basic requirements, a written test is administered.

The test comprises a proofreading exercise and the writing of 2 replies to letters received by the Minister. A pass mark of $65 \%$ is required. If the applicant is successful at the written test, an oral interview is conducted. As you can see, the standards for hiring DSC writers are quite high; unfortunately, so is the fallure rate for the written test!

Results from many tests consistently indicate that the majority of applicants do not approach the subject matter logically. They cotally overlook key elements and address insignificant points at great length making the replies long and awkward.

Just as consistent is the problem of poor style. Individuals are not expected to know the style of the Minister but simply the basics of good business style and tone. Quite of ten the replies are overly friendly or rhetorical rather than concise and straightforward.

Once an individual is chosen as a DSC writer, a training programme specifically designed for the needs of the present Minister begins. 
Writers are given a "DSC Style Manual" and their work is reviewed and monitored for up to six months to ensure that they are meeting our high standards.

All this training and monitoring is necessary because we can no longer assume that possession of a university degree automatically means that the university graduate has good writing skills and can think logically and clearly. In fact, a great number of welleducated individuals pepper their texts with words and phrases such as, "scenario, back-burner, head honcho, and bucking it up the line"! One recent graduate stated in her résumé that "...(I) enjoy the creative challenge involved in the application of dialectical reasoning in any subject matter requiring a synthesis":!

We try to train our writers to write clear, concise texts that are easily understandable. Superfluous wording, bureaucratic gobbledegook and the latest jargon are not acceptable. The basic idea is to get the message across in good, plain English. The text may not sound as important once we have stripped it down but the message will certainly be much clearer.

So, do not believe all those stories claiming that government letters and texts are all complex and incomprehensible. We are doing our best to communicate clearly and simply and, remember, if you receive a letter stating -

"It must be recognized that this is not a normal business transaction but rather a political item so far as the U.K. authorities are concerned, accordingly, whilst continued efforts will be made by all Canadian offictals the likelyhood (sic) of any successful completion in the forseeable (sic) future is most unlikely." -it won't be from Transport Canada!

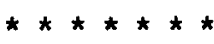

Over the past twelve years, Serafina Sebastyan has had experience in editing, writing and publishing in several federal government departments. She now manages the Executive Correspondence Unit of Transport Canada and holds a B.A. Honours in English and French Literature and a Master's degree In French Language and Literature.

\section{WRITING WORD PROCESSOR MANUALS FOR A LAY PUBLIC}

Karin Montin

I am going to discuss some of the problems involved in writing easy-to-understand instructions for word processing almed chiefly at secretaries and typists.

In particular, I will be looking at some ways of adapting vocabulary to the reader's experience and reading abillty and conforming sentence structures to a few rules of thumb.

My experience has been as a writer of user training manuals for a large manufacturer of word processors.

Writing user documentation for word processing is technical writing, since it involves describing and explaining complex electronic functions. It can equally well be described, however, as nontechnical writing, since tt is intended for nontechnicians.

\section{WORD PROCESSING}

A word processor is a specialized computer that can be most simply described as a fancy typewriter. It looks like a combination typewriter and television screen, although the typewriter is split into keyboard and printer. The keyboard has some extra keys which make 1t possible to do more than just type.

A word processor can do many things, but 1ts primary function is to display what you have typed before you print $1 t$ on paper. Since typing and printing are separate steps, it is possible to make any number of changes to the typed page before it is committed to paper. The second major function is to store a typed page on disk the way a tape recorder stores a song on tape, making 1t possible to play 